\title{
CRIPTOMOEDAS E O PLANEJAMENTO TRIBUTÁRIO
}

\author{
Flávio Couto Bernardes ${ }^{1}$ \\ Suélen Marine Silva ${ }^{2}$
}

\section{Resumo}

O objetivo do artigo é o estudo das criptomoedas, em especial a Bitcoin, como mecanismo de planejamento tributário. O uso da criptografia garante a segurança e anonimato das transações com as criptomoedas. Diante do crescente uso das criptomoedas, começaram a ocorrer questionamentos sobre negócios jurídicos realizados com a Bitcoin, em especial na seara da tributação. Sendo assim, questiona-se se as criptomoedas podem ser utilizadas como planejamento tributário. A metodologia adotada foi a qualitativa, com leitura de artigos científicos, análise da regulamentação normativa no âmbito do direito brasileiro. Ao final conclui-se que as criptomoedas podem ser utilizadas como planejamento tributário.

Palavras-chave: Criptomedas; Bitcoin; Tecnologia; Planejamento Tributário; Evasão de Divisas

\section{CRYPTOCURRENCIES AND THE TAX PLANNING}

\begin{abstract}
:
The purpose of the article is study of cryptocurrencies, especially Bitcoin, as tax planning mechanism. The use of encryption guarantees security and anonymity of transactions with cryptocurrencies. In face of the growing use of cryptocurrencies, questions began to occur about legal deals carried out with Bitcoin, especially in field of taxation. Therefore, it is questioned whether cryptocurrencies can be used in tax evasion. The adopted methodology was the qualitative one, reading of scientific articles, analysis of the normative regulation in the scope of the Brazilian law. In the end it is concluded that cryptocurrencies can be used in tax evasion.
\end{abstract}

Keywords: Cryptocurrencies; Bitcoin; Technology; Tax Planning; Tax Evasion

\section{INTRODUÇÃO}

\footnotetext{
${ }^{1}$ Doutor (2006), Mestre (2000) e Bacharel (1994) em Direito pela Universidade Federal de Minas Gerais. Membro do corpo docente do Programa de Pós-Graduação em Direito da Pontifícia Universidade Católica de Minas Gerais. Professor de Direito Tributário e Financeiro da UFMG. Procurador do Município de Belo Horizonte. Secretário da Associação Brasileira de Direito Tributário - Abradt. Advogado. E-mail: flavio.bernardes@ bernardesadvogados.adv.br

${ }^{2}$ Advogada. Mestre em Direito (2020) pela Pontifícia Universidade Católica de Minas Gerais. Especialista em Direito de Empresa (2017) e Direito Processual (2017) pelo Instituto de Educação Continuada da PUC Minas. Bacharel em Direito pela Pontifícia Universidade Católica de Minas Gerais. Endereço Eletrônico: suelen_marine@yahoo.com.br
} 
A realidade é latente: o mundo globalizado se torna cada vez mais digital. Significativa parte das atividades humanas ocorre através da internet, sendo que a própria utilização dos recursos financeiros, ou seja, das moedas, tem sido realizada através do denominado ambiente virtual, sem sua circulação física, como se verifica pelas operações bancárias em geral e o crescimento recorrente do uso de cartões magnéticos.

A regulamentação da atividade financeira é realizada pelos diversos países, sendo que a fluidez do capital entre as nações é tão expressiva que a matéria passou a ser igualmente normatizada através de uma série de tratados internacionais, buscando preservar a segurança do sistema financeiro que, em última análise, consiste na proteção dos seus usuários, isto é, dos cidadãos. Este controle rígido, no entanto, não evitou a impactante crise econômica de 2008, que teve sua maior repercussão na economia dos Estados Unidos da América - EUA, especialmente nas suas instituições financeiras, em razão do sofisticado modelo implementado no sistema financeiro mediante a adoção de algumas modalidades de novas operações que não estavam devidamente monitoradas, demonstrando sua fragilidade neste aspecto.

Apesar do rígido controle normativo deste relevante setor econômico, sua regulamentação não foi capaz de identificar a ausência de lastro financeiro de algumas empresas do setor, sobretudo em virtude das inovadoras operações empreendidas exclusivamente no âmbito digital e com reflexos contábeis que não foram identificadas e revisadas a contento pela fiscalização. Esta breve contextualização é importante apenas para apontar o cenário da origem das denominadas criptomoedas. Neste exato período que uma pessoa ou um grupo de pessoas ou empresas, intitulado Satoshi Nakamoto, publicou um paper, num fórum online sobre criptografia, comentando sobre aquela que é considerada a mais famosa das moedas digitais: a Bitcoin.

Bitcoin é uma moeda virtual, a mais antiga e conhecida, que vem despertando interesse da coletividade, haja vista que durante um período passou a ser considerada um bom investimento especulativo, devido à sua volatilidade, além de ser anônima e não necessariamente deixar rastro sobre os volumes das operações, locais e respectivos titulares, pois os titulares podem se identificar por pseudônimos. Praticamente uma cártula de crédito para fins de circulação com titularidade ao portador, como há muito foi conhecido no setor dos títulos de crédito ou no mercado societário. 
A criptomoeda não é emitida pelo Estado, mas sim por um programa de computador que lança algoritmos para que os computadores, por meio de cálculos matemáticos, minerem a moeda digital liberando blocos de Bitcoin na Blockchain. Esta última é exatamente a tecnologia que torna segura a intitulada mineração e o uso da Bitcoin. É uma espécie de livro público de registro das moedas digitais e sua segurança é garantida pela criptografia, tudo sem controle público através do sistema financeiro dos países.

Muitos atos e negócios jurídicos têm sido realizados por meio das moedas digitais, despertando o interesse da comunidade jurídica devido às implicações que possuem. Diante das características apontadas, principalmente a ausência do controle público e do reconhecimento do lastro de sua titularidade vinculada a um CPF ou a um CNPJ a cada operação, surgiu o inevitável questionamento: poderia o recurso financeiro vinculado às criptomoedas tornar-se um mecanismo para impulsionar a evasão fiscal? Justamente para responder a este problema proposto que a presente pesquisa foi realizada, confrontando os aspectos conceituais e normativos das criptomoedas e do instituto jurídico denominado evasão fiscal para propor as conclusões aqui traçadas.

O primeiro capítulo trata da natureza jurídica das criptomoedas, traçando paralelo com as moedas tradicionalmente conhecidas, elucidando seu mecanismo de funcionamento e controle. Isto porque, a criação das moedas digitais é descentralizada e ainda não tem regulação Estatal no Brasil, sendo obtida a partir da chamada mineração por programa de computador ligado constantemente na rede, cujo gestor e usuários não são identificáveis de plano.

O capítulo seguinte visa analisar os conceitos de elisão, elusão e evasão fiscal, bem como a norma geral antielisiva contida no parágrafo único do artigo 116 do CTN.

Por fim, será abordado a possibilidade da comercialização das criptomoedas para esta finalidade de planejamento tributário, apresentando conclusões que buscam contribuir para o debate acadêmico desta importante matéria, que terá vasto campo científico a partir do crescimento acelerado de sua utilização.

O tema é pertinente para a atualidade, haja vista que há o Projeto de Lei n. 2.303/2015, que visa restringir, impedir e criminalizar as criptomoedas no país. Logo, naturalmente que este estudo não tem a ilusória pretensão de esgotar o tema das criptomoedas e a tributação, mas ser estímulo para seu debate na seara das novas tecnologias e seus reflexos na tributação. 


\section{NATUREZA JURÍDICA DAS CRIPTOMOEDAS.}

Antes de adentrar no estudo do que são as criptomoedas, importante ressaltar que apesar de sua denominação, este instituto jurídico não está inserido no modelo tradicional das moedas corrente utilizadas no mercado financeiro, como se depreende do sistema normativo pátrio, o que tem acarretado divergências inclusive no tocante à sua natureza.

A Constituição da República estabelece no artigo 21, inciso VII, que é competência da União emitir moedas. No mesmo sentido o artigo 48, inciso XIV, prevê que é atribuição do Congresso Nacional, com veto do Presidente da República, dispor sobre moeda e seus limites de emissão. Por fim, o artigo 164 dispõe que a competência da União para emitir moedas será exercida exclusivamente pelo Banco Central.

Pois bem, as criptomoedas não são emitidas pelo Banco Central e tampouco tem lei ou algum órgão estatal que regulamentam ou as definem com a natureza jurídica de moeda, nos moldes previstos no texto constitucional. São originadas na internet por meio de softwares próprios e tem sua produção descentralizada (SOUZA, 2017, p. 62).

Na rede, há computadores ligados entre si, chamados de nós, no qual os dados ficam disponíveis para todos e não apenas em um único servidor. Essa característica faz com que a tecnologia que emite as criptomoedas seja segura e praticamente impossível de ser invadida por hackers. (SILVA, 2017, p. 109)

Ressalta-se que quando se tem notícia do furto efetuado de criptomoedas por parte usualmente dos denominados hackers ${ }^{3}$, este ilícito não ocorreu na Blockchain e sim no servidor do proprietário da criptomoeda, normalmente por ter deixado seus dados no servidor comum, com acesso de pessoas e dos citados profissionais que invadem os computadores para capturar ditas informações. (SILVA, 2017, p. 109)

Para que haja falha na rede do sistema que emite as criptomoedas, seria necessário que todos os computares da rede sofressem ataque ou fossem desligados simultaneamente, o que dificilmente aconteceria, pelas informações divulgadas até o momento e mencionada pelos conhecedores desta área do conhecimento científico, como a seguir será destacado. (SILVA, 2017, p. 109)

\footnotetext{
${ }^{3}$ Hacker é uma palavra em inglês do âmbito da informática que indica uma pessoa que possui interesse e um bom conhecimento nessa área, sendo capaz de fazer hack (uma modificação) em algum sistema informático. Em inglês, a palavra hack é um verbo que significa cortar alguma coisa de forma irregular ou grosseira.
} 
A essa rede é dado o nome de Blockchain, que pode ser aberta ou privada aos usuários, buscando garantir transparência, imutabilidade e desintermediação das transações efetuadas neste sistema, haja vista que as informações contidas devem ser validadas por todos os computadores, o que dificulta acentuadamente a possibilidade da existência de fraudes. Ressalta-se também que a Blockchain é uma espécie de livro criptografado pela rede, no qual todas as atividades e transações com a criptomoedas são registradas.

As criptomoedas não são geradas de acordo com a vontade de alguém. Na referida rede os blocos de algoritmos são liberados e os softwares trabalham nos complexos problemas matemáticos, que quando solucionados emitem a moeda virtual. A esse trabalho de "extração" da moeda virtual deu-se o nome de mineração. Quando a moeda é liberada na rede, ela é adicionada à Blockchain. Sobre esse processo FOLLADOR (2017, p. 85) elucida:

\begin{abstract}
Os "mineradores" (miners) são pessoas ou empresas (ou grupos deles - mining pools) que põem seu poder computacional - e o espaço, energia etc. a ele relacionados - para resolver complexos algoritmos destinados a verificar a higidez dos blocos de transações, em especial com vistas a evitar o duplo gasto de um mesmo bitcoin. Quando concluem a análise de um grupo de transações, os mineradores geram um bloco, que submetem à validação pelos "nós" (nodes) da rede, isto é, computadores que atualizam progressivamente a Blockchain. Para lograrem sucesso, os mineradores dependem não apenas de poder computacional, mas também de um pouco de sorte, na medida em que, para que um novo bloco, seja efetivamente adicionada a Blockchain, deve ser aceito por outros nodes, que o validam e passem a utilizá-lo, como ponto de partida, isto é, como última atualização da Blokchain. Sendo bem-sucedido, o minerador ganha uma recompensa (mining reward), em bitcoins. A cada novo bloco de transações incorporada à Blockchain. Como há no protocolo do sistema, um número limite de 21 milhões de bitcoins a serem gerados, torna-se progressivamente mais difícil minerar bitcoins e progressivamente menor - se contada em número de bitcoins - a remuneração dos mineradores.
\end{abstract}

As transações realizadas no ambiente virtual não necessitam da intermediação de instituição financeira, sendo realizadas diretamente entre as partes através da rede peer-topeer $(\mathrm{P} 2 \mathrm{P})$, na Blockchain. Sobre as transações nesta rede, DENNY, PAULO e CASTRO (2017, p. 131) comentam:

Trata-se de um novo tipo de banco de dados que permite que vários usuários compartilhem informações e possam modificá-las de forma segura e confiável, mesmo que não confiem uns nos outros. Esse banco de dados integra usuários numa rede peer-to-peer (P2P), portanto sem qualquer gerente ou coordenador. Mas faz isso de tal forma a alcançar um acordo entre participantes, consistente e confiável, sobre um registro de eventos (por exemplo, "quem atingiu a meta"). 
Ainda sobre a rede peer-to-peer, MARINHO e RIBEIRO (2017, p. 151) trazem as seguintes considerações:

\begin{abstract}
A tecnologia de Blockchaim pode ser conceituada como um sistema de banco de dados distribuídos que funciona como um instrumento de registro que permite a transferência de valores/informações sem a existência de uma autoridade central de validação. Essa validação é feita de maneira compartilhada e descentralizada por meio de uma rede peer-to-peer. É como se os dados do livro-caixa da empresa fossem gravados, tivessem sua origem e conteúdo confirmados em vários computadores em rede, de maneira quase simultâneos, e uma vez introduzidos, tais dados não pudessem ser mais alterados por uma parte e o acesso ao seu conteúdo estivesse à disposição de todos os membros da rede.
\end{abstract}

Importante ressaltar que em todas as operações, desde a mineração das criptomoedas até a sua efetiva transação, os dados são protegidos por criptografia. Nesse sentido, explica ANDRADE (2017, p. 48):

\footnotetext{
A tecnologia que envolve as criptomoedas capta os dados de segurança e criptografa os caracteres para protegê-los e. especificamente no caso das bitcoins, para manter as transações financeiras em sigilo. Por um lado, essa codificação tende a gerar segurança no uso dos dados; entretanto, pode inviabilizar o controle e a regulamentação sobre as transações.
}

Considerando os conceitos adotados para a elucidação da origem da criptomoeda, que se utiliza efetivamente de variáveis buscadas na esfera de outra área do conhecimento, que envolve a Ciência da Computação e a Tecnologia da Informação, torna-se necessário analisar como se daria seu enquadramento jurídico, já que a mesma é adquirida e utilizada em negócios jurídicos, acarretando a dúvida sobre sua natureza de moeda ou ativo de diversa natureza.

O gênero moeda virtual, no sentido lato, divide-se em dinheiro eletrônico (e-money) e moeda virtual no sentido stricto. Dinheiro eletrônico é a representação da moeda nacional usada em transferências de dinheiro, como o Dólar, o Real, o Euro. Já a moeda virtual no sentido stricto pode ter características das moedas nacionais, haja vista que podem ser usadas como meio de troca e/ou reserva de valor. A moeda virtual pode se subdividir em não conversível ou fechada, ou conversível ou aberta, conforme tenham, ou não, valor equivalente em moeda oficial.

Também podem ser classificadas em centralizadas ou descentralizadas. Nas centralizadas existe um intermediador entre pagador e recebedor, sendo que nas 
descentralizadas não há controle por ninguém na emissão, transferência, distribuição, preço, transações ou qualquer outra modalidade de negócio jurídico. Baseada exatamente nestes critérios, as criptomoedas são conceituadas como:

moedas virtuais, descentralizadas, criptografadas e seguras, utilizadas para intermediar a realização de negócios jurídicos no ciberespaço, agindo de forma substitutiva à moeda física e afastando a necessidade de intermediários fiduciários, que oneram as transações e o risco de falsificação, fraudes e depreciação da moeda. (SOUZA, 2017, p. 65)

Já MARINHO e RIBEIRO (2017, p. 153) conceituam as criptomoedas "como um bem digital construído como meio de troca, com base na tecnologia da criptografia, para garantir o fluxo transacional, bem como para controlar a criação de unidades adicionais de moeda".

Verifica-se, diante da informação de que as criptomoedas são obtidas por intermédio de programas de computador, que resta claro que a Bitcoin não é moeda corrente utilizada pelo Sistema Financeiro e emitida pelo Banco Central por determinação constitucional, mas se pode considerá-la como moeda virtual, por ser utilizada como forma de pagamento no ambiente virtual. Ademais, a alta volatilidade devido a grade procura da Bitcoin fez com que passasse a ser utilizada como investimento.

Fernando Ulrich (2014, p. 44 - 45) elucida que a Bitcoin é uma válvula de escape para quem deseja alternativa à moeda de seu país e para quem deseja evadir-se dos efeitos danosos dos controles de capitais e da má gestão de bancos centrais. Prossegue explicando que:

Como bitcoins são no seu cerne, simplesmente pacotes de dados, eles podem ser usados para transferir não somente moedas, mas também ações de empresas, apostas, informações delicadas. Alguns dos atributos que estão embutidos no protocolo do Bitcoin incluem micropagamentos, mediações de litígios, contratos de garantia e propriedade inteligente.

Dessa forma, resta claro que a bitcoin possui valor monetário, podendo ser considerada sua natureza jurídica, no ordenamento pátrio, como um ativo não financeiro e não como moeda, sendo considerada um acréscimo patrimonial para quem a possui. Ademais, o Banco Central do Brasil já se pronunciou sobre a moeda virtual no Comunicado $n$. 25.306/2014, no qual deixa claro que não se equipara a moeda corrente para fins de comercialização e câmbio, destacando o risco de sua aquisição e transações devido à 
volatilidade, além do risco pela ausência de lastro perante o sistema financeiro. Destaca, nesta linha, que a moeda virtual não se confunde com a moeda eletrônica de que trata a Lei n. $12.865 / 2013$.

Esclarece, portanto, que a moeda virtual não é garantida por autoridade monetária e, assim, sua troca em dinheiro corrente não pode ser garantida pelo Estado. Também há o alerta de que as referidas moedas podem ser usadas em atos ilícitos, alertando o possuidor de boa-fé quanto à origem de sua aquisição.

A Secretaria da Receita Federal do Brasil - SRFB se pronunciou reconhecendo a criptomoeda como ativo financeiro da pessoa física ou jurídica para todos os fins, como assevera ANDRADE (2014, p. 54):

\begin{abstract}
Em abril de 2014, a Receita Federal do Brasil, estabeleceu como trataria a detenção e o uso de bitcoins e outras moedas digitais. O Brasil está tratando as moedas digitais como ativos financeiros, com a Receita Federal impondo um imposto de $15 \%$ sobre os ganhos de capital no momento da venda, no entanto, existem algumas diferenças importantes que podem ser positivas para os usuários de bitcoins no país. Aqueles que vendem menos moedas com um valor inferior a $\mathrm{R} \$ 35.000,00$, não terão de pagar o imposto. Isso significa que os usuários de bitcoin no Brasil não terão de calcular os impostos sobre ganhos de capital ao fazer pequenas compras. A Receita Federal também exige declarações de contas anuais daqueles que possuem mais de $\mathrm{R} \$ 1.000,00$ em participações em moeda digital.

Em maio de 2017, A Receita Federal do Brasil incluiu a bitcoin nas instruções da declaração anual do Imposto de Renda de 2017, devendo ser declarado na Ficha Bens e Direitos como "outros bens", uma vez que pode ser equiparado a um ativo financeiro.
\end{abstract}

Lado outro, a Comissão de Valores Mobiliários - CVM também se posicionou no sentido de que as moedas digitais não são ativos financeiros, vetando sua aquisição pelos fundos de investimento, sob a justificativa de preservar os investidores neste mercado. Assim se manifestou a CVM (2018):

\begin{abstract}
Assim e baseado em dita indefinição, a interpretação desta área técnica é a de que as criptomoedas não podem ser qualificadas como ativos financeiros, para os efeitos do disposto no artigo $2^{\circ}, \mathrm{V}$, da Instrução CVM $\mathrm{n}^{\circ} 555 / 14$, e por essa razão, sua aquisição direta pelos fundos de investimento ali regulados não é permitida
\end{abstract}

Giro outro, países como a Austrália, Áustria, Bélgica, Cuba, Japão, Espanha, Reino Unido e outros, consideram as criptomoedas legais e moedas correntes. Países como Canadá e Alemanha consideram as criptomoedas como legais e moedas comerciais. Já países como Brasil, França, Hong Kong, Israel, Holanda, Noruega, Suíça, Estados Unidos e Venezuela 
consideram as criptomoedas como commodites e apenas Brasil e Venezuela não possuem norma que proíbem ou permitam o uso e aquisição das moedas virtuais. Apenas a Polônia considera as criptomoedas como propriedade e legal e a Índia mesmo sem ter norma proibitiva a considera como dinheiro (ANDRADE. 2017, p. 52-54).

Por fim, o economista português Fernando Urich (2014, p. 139) assevera que a Bitcoin deve ser explicada ao jurista da seguinte forma:

\begin{abstract}
Bitcoins, como unidade monetária, são mais bem consideradas um bem incorpóreo que, em certos mercados, têm sido aceitos em troca de bens e serviços. Poderíamos dizer que essas transações constituem uma permuta, e jamais venda com pagamento em dinheiro, pois a moeda, em cada jurisdição, é definida por força da lei, sendo uma prerrogativa de exclusividade do estado.
\end{abstract}

Até março de 2018 havia 1.542 tipos de criptomoedas sendo comercializadas (BAL, 2018), dentre elas a Ethereum, a Ripple, a Litecoin, a Dogecoin, a Feathercoin, a ZCash, a Monero e a Dash. A mais antiga e mais famosa das cripotmoedas, que vem levantando interesse da comunidade jurídica devido à sua volatilidade, é a Bitcoin, motivo de sua abordagem no tópico seguinte.

\title{
1.1. A Bitcoin.
}

Mais antiga e famosa criptomoeda, a Bitcoin foi criada por Satoshi Nakamoto, no final do ano de 2008, com a publicação de um paper num fórum online sobre criptografia. Seu autor ainda é desconhecido, motivando a curiosidade e mesmo o objetivo jurídico de seu conhecimento, exatamente por não se ter a identificação se se trata de uma pessoa física, uma pessoa jurídica ou a designação de um grupo de pessoas físicas ou empresas. Outros vão além e dizem que o nome Satoshi Nakamoto é a junção das iniciais dos nomes das gigantes da tecnologia Samsung, Toshiba, Nakamichi e Motorola (MARINHO E RIBEIRO. 2017, p. 153).

Outro ponto interessante para se ressaltar é que a criação da Bitcoin se deu no cenário da crise financeira de 2008, que atingiu especialmente os EUA e a União Européia, apresentando-se a criptomoeda como alternativa ao sistema financeiro atual no tocante à realização de investimentos e sua condição de ativo negociável. 
A popularização da Bitcoin, segundo TEIXEIRA e SILVA (2017, p. 108), se deu devido " a instabilidade do sistema financeiro, a forte intervenção estatal em suas operações, em especial a ausência de privacidade financeira, que perduram por séculos e a cada tempo o grau de intervenção estatal tende a aumentar".

Quando há blocos na rede para serem validados pelos computadores da Blockchaim, deve-se tomar o cuidado para não haver bifurcações (forks), o que pode fazer com que um mesmo bloco de algoritmos venha a ser minerado dos dois lados opostos. Essa bifurcação da rede gera uma divisão nas Bitcoins que são chamadas de Bitcoins-cash e Bitcoin gold, "cada qual com sua específica rede, com um nível distinto de aceitação no mercado e consequentemente, com um valor também diferente" (FOLLADOR, 2017, p. 81). A rede de Bitcoin está programada para emitir novas moedas até o ano de 2140.

Para usar a Bitcoin é necessário ter no computador os softwares específicos e criar as chaves criptográficas que são únicas para cada usuário. Assim que for criada a referida chave, o usuário poderá comprar a Bitcoin em moeda corrente regulamentada no mercado financeiro e ela será armazenada em uma carteira digital.

Esta criptomoeda pode ser usada em vários negócios jurídicos, com diferenciadas implicações, que não fazem parte da delimitação metodológica do presente trabalho, desde já justificando que não serão abordadas. A título de exemplo, pode ser usada como permuta de bens, doação ou dação em pagamento, sendo que sua compra e venda não é possível, por não se tratar de moeda corrente sujeita a regular operação de câmbio no Brasil ${ }^{4}$. ANDRADE, (2017 p. 52) elucida que no Japão a bitcoin é legalizada e classificada como moeda corrente, já na Polônia a Bitcoin é legalizada e classificada como propriedade.

Já o usuário que visa o lucro deve realizar operações em blocos na Blockchaim e especular sua Bitcoin em diversas plataformas. Esta moeda digital possui cotações diárias e em dezembro de 2017 atingiu a marca de U\$15.000,00 (quinze mil dólares americano) a unidade, com significativa queda em maio de 2018, sendo que o relatório Goldman Sachs prevê que a criptomoeda deve continuar em queda (SOUZA. 2017, p. 62). A cotação da

\footnotetext{
${ }^{4}$ A Bitcoin foi regulamentada como método de pagamento oficial no Japão no começo de 2017. Na visão do governo japonês, essa foi a forma encontrada para dar controle a um ativo descentralizado e independente de decisões governamentais ou do sistema bancário convencional. Na época da regulamentação, o primeiroministro Shinzo Abe forçou as exchanges a se adequarem a normas financeiras básicas para evitar lavagem de dinheiro. Disponível in: <https://www.istoedinheiro.com.br/o-outro-lado-da-moeda-4/>.
} 
Bitcoin na data em que o presente artigo foi escrito atingiu o valor de $\mathrm{R} \$ 35.339,49$ a unidade, segundo o site Mercado do Bitcoin ${ }^{5}$.

Toda transação realizada com a Bitcoin é anônima, já que não há servidor específico, e sim uma rede com vários computadores que dividem os dados, não tornando possível determinar o local e em qual IP (endereço do computador na rede) foi realizada a transação e também pode ser utilizado pseudônimo no registro de propriedade da Bitcoin na rede. Justamente por isso que se afirma que a operação com a Bitcoin não deixa lastro.

Lado outro, diante da falta de regulamentação sobre o tema e a crescente demanda de que haja uma definição sobre a utilização das criptomoedas e suas respectivas garantias, encontra-se em trâmite o Projeto de Lei n. 2.303/2015, que pode restringir, impedir ou criminalizar as negociações das moedas digitais.

No texto do referido projeto de lei, as criptomoedas poderão ser comercializadas entre pessoas, mas serão proibidas de ser negociadas por empresas. Essa proposta não é a melhor para o tema, haja vista que atualmente se trata de uma unidade de troca global, com contínuo crescimento do comércio digital, tratando-se de manifesta usurpação da liberdade das pessoas e da livre iniciativa, garantias consagradas no texto constitucional. Entretanto, também devido ao recorte metodológico essas questões não serão tratadas no presente artigo, sendo nosso foco apenas a questão do uso da Bitcoin na evasão fiscal.

Indubitavelmente que a melhor solução é apenas estabelecer as vedações para sua utilização em situações ilícitas e o formato de como poderá ser definida contratualmente, embora os mecanismos de vinculação como garantia ainda não se encontrem claros do ponto de vista técnico-operacional.

\section{EVASÃO FISCAL NO ORDENAMENTO JURÍDICO.}

A contextualização, assim como a definição da natureza jurídica, das criptomoedas são necessárias para sua análise quanto à possibilidade da realização de negócios jurídicos que podem ser elencados conceitualmente na condição de elisão e evasão fiscal, além do uso para elidir ou evadir divisas ${ }^{6}$.

\footnotetext{
${ }^{5}$ Cotação Bitcoin. Disponível in: 〈https://www.mercadobitcoin.com.br/negociacoes〉.

${ }^{6}$ Sobre o tema ver: Torres, Heleno Taveira. "Direito Tributário e Direito Privado: autonomia privada, simulação, elusão tributária?. São Paulo: Revista dos Tribunais, 2003.
} 
A elisão fiscal se caracteriza por ser o meio lícito no qual o contribuinte faz arranjos negociais com a finalidade de pagar menos tributos. Esses arranjos são realizados em virtude da ausência de previsão expressa de sua utilização na legislação tributária, possibilitando os chamados planejamentos tributários, que têm por objetivo a economia no pagamento de tributos e maximização dos lucros. $\mathrm{O}$ ato elisivo precede a ocorrência da hipótese de incidência do tributo e encontra forte resistência do Fisco e de algumas correntes doutrinárias ${ }^{7}$.

A Constituição da República estabelece que ninguém será obrigado a fazer ou cumprir algo que não esteja previsto em lei, no caso da elisão a ausência de regulamentação normativa possibilita que o contribuinte diminua seu ônus tributário.

Míster ressaltar que elisão e elusão fiscal são formas de arranjos distintos. Enquanto a elisão fiscal é a forma lícita de pagar menos tributos por meio de planejamento tributário simples, a elusão fiscal é o planejamento tributário agressivo, que se efetivaria através da intitulada fraude à lei e abuso da forma, o que o tornaria um ato ou negócio jurídico ilícito ${ }^{8}$.

Já a evasão tributária é ato ilícito que consiste na prática de um negócio jurídico por meio de simulação, fraude ou sonegação de tributos. Trata-se da omissão do pagamento do tributo ou simulação para encobrir o fato gerador, com manifesta vontade dolosa em ocultar os elementos do fato gerador. Exemplo de evasão fiscal é quando o indivíduo, por meio fraudulento, declara valor menor a fim de reduzir a carga tributária incidente, como se verifica no exemplo de quem compra um imóvel por 1 milhão reais e em acordo com o vendedor declaram no registro de imóveis que pagou/recebeu 500 mil reais. Sobre a Evasão Fiscal FERRAZ, GODOI e SPAGNOL (2014, p. 341) elucidam:

Se o contribuinte evita, reduz ou posterga o pagamento dos tributos por meio de condutas ilícitas, que implicam infração do ordenamento jurídico, tem-se o fenômeno que se designa genericamente com a expressão evasão tributária. Neste caso, que no Brasil também pode ser denominado de sonegação tributária, o contribuinte pratica o fato gerador da obrigação e busca de maneira fraudulenta escapar do dever de recolher o tributo.

\footnotetext{
${ }^{7}$ Sobre a norma anti-elisiva ver: BERNARDES, Flávio Couto. MIRANDA, Vitor Pimenta de. Planejamento Tributario e Segurança Jurídica. Planejamento Tributário e Segurança Jurídica. Revista ABRADT Fórum de Direito Tributário, v. 03, p. 125-146, 2018.

${ }^{8}$ Sobre o tema ver: Torres, Heleno Taveira. "Direito Tributário e Direito Privado: autonomia privada, simulação, elusão tributária?. São Paulo: Revista dos Tribunais, 2003.
} 
Nesse sentido, o legislador visando coibir a pratica da evasão fiscal positivou o parágrafo único do artigo 116 do CTN determinando que

\begin{abstract}
A autoridade administrativa poderá desconsiderar atos ou negócios jurídicos praticados com a finalidade de dissimular a ocorrência do fato gerador do tributo ou a natureza dos elementos constitutivos da obrigação tributária, observados os procedimentos a serem estabelecidos em lei ordinária.
\end{abstract}

Como bem teoriza Alberto Xavier, a presença de uma cláusula geral antielisiva em dado ordenamento jurídico tem como finalidade a cobrança de tributo, por analogia, de dados atos ou negócios jurídicos classificados como extratípicos, ou seja, que não se constituem como fato oponível à norma tributária, mas que na verdade produzem efeitos econômicos similares ou iguais aos daqueles atos ou negócios jurídicos que se aperfeiçoam como fatos típicos. Nessa hipótese, o efeito econômico extratípico não seria alcançado pela norma tributária, uma vez que não estaria dentro do escopo da legalidade. A norma geral antielisiva, então, daria ao aplicador/intérprete a possibilidade de desconsiderar o ato ou negócio jurídico realizado pelos particulares por considerar que, em verdade, teria sido concretizado com o intuito de encobrir os efeitos econômicos que teriam sido alcançados por outro ato ou negócio jurídico que estaria previamente contido em uma hipótese de incidência tributária $(2001$, p. 85 e s.).

A norma geral antielisiva, nesse sentido, se baseia na utilização de método analógico para que a tributação possa ocorrer. A presença de uma norma geral antielisiva em dado ordenamento que estipula o princípio da tipicidade e da legalidade em matéria tributária, no nível constitucional, acaba por gerar grandes desafios para os intérpretes e, especialmente, para aqueles que pretendem sustentar essa possibilidade. Os malabarismos teóricos são extremamente arriscados e, com todo o respeito àqueles que pensam de maneira divergente, acabam por desnaturar o cerne do próprio sistema de tributação a partir de uma perspectiva da ciência do direito tributário.

A questão, então, é verificar se do ponto de vista do sistema jurídico brasileiro haveria a possibilidade de se estabelecer uma norma geral antielisiva. Não se admitindo essa hipótese, a questão seria como dar interpretação adequada à norma contida no parágrafo único, do artigo 116, do Código Tributário Nacional.

\title{
2.1. Pressupostos teóricos da tributação no sistema brasileiro
}


A aplicação das normas jurídicas de natureza tributária, assim como em todas as demais áreas do Direito, exige a formulação de rigor técnico para sua efetivação. Esse rigor somente é alcançável a partir da tomada de premissas teóricas e normativas gerais que, ao final, serão corroboradas a partir de raciocínio calcado em precisão lógica e metodológica. Essa obviedade, que muitos têm dificuldade de absorver quando da aplicação da norma tributária, tem como finalidade precípua defender que dentro da estrutura de um raciocínio silogístico não há espaço para paralogismo, ou seja, para a integração de premissas alheias às formulações principiológico-normativas gerais sobre o caso concreto, a causar a formulação de uma conclusão mais próxima ao querer do intérprete, e não ao querer da lei.

Seguindo essa lógica, chega-se à teorização acerca dos princípios da legalidade e da tipicidade tributárias (art. 150, I, da Constituição Federal de 1988) como norteadores para a técnica de aplicação da norma jurídica tributária. A matriz jurídica de Direito Público se dá conforme relações de subordinação entre o Fisco e o particular. Nesse vínculo jurídico, somente resta ao particular invocar as bases da ideia de Estado de Direito, qual seja, a submissão do Estado e de seus agentes à própria lei. Evitar o arbítrio, eis a tônica da tributação. Tomado esse pressuposto básico, a legalidade e a tipicidade acabam por gerar a configuração de uma subordinação limitada: se dá de acordo com os limites estipulados pela lei, e somente dentro desses limites, não se admitindo, por dedução basilar, que haja a possibilidade de lançar mão de métodos integrativos, como a analogia, para ampliar o escopo de uma dada norma tributária.

O segundo nível básico da argumentação deve levar em consideração, por coerência, que as relações jurídica de Direito Privado são lastreadas pelo viés da coordenação. Significa que a regra basilar da legalidade, direito fundamental (art. $5^{\circ}$, II, da Constituição Federal de 1988), se dá no sentido de que a atividade dos particulares estão permitidas, desde que não haja, expressamente, proibição legal. Dessa forma, aquilo que é expressamente permitido e não colocado como obrigatório ou proibido por parte do sistema jurídico, pode ser utilizado pelos agentes privados no intuito de realizarem um dado modelo negocial.

Conclui-se, preliminarmente, que a tributação invoca a formulação de norma jurídica que estabelece um dever específico, cristalino e preciso para o particular. Por sua vez, a vontade do particular ao realizar um ato ou negócio jurídico, se move na zona de permissão geral própria à matriz constitucional que se assenta na segurança jurídica e na lógica do 
Estado de Direito. Então, para que a prática de um ato ou negócio jurídico seja tributado, deve ocorrer duas condições necessárias: primeiro, que estes fatos sejam típicos, dentro da lógica tributária. Segundo, que não sejam proibidos nem obrigatórios quando da análise do ordenamento, tendo em vista que todas as demais ações individuais estão dentro da zona de permissibilidade que conforma direito fundamental.

\subsection{Existe uma norma geral antielisiva no ordenamento jurídico brasileiro?}

Superadas as premissas anteriores, parte-se para a identificação de um cenário em que se possa considerar, a partir de uma visão científica, seja possível se introduzir no sistema jurídico brasileiro uma norma geral antielisiva.

A finalidade da norma geral antielisiva é combater determinadas ações dos particulares que, a partir de uma análise interpretativa extremamente discricionária e aberta, possam ser consideradas como um modo de burla à hipótese de incidência, praticando-se fato não oponível. A primeira questão que surge é como manter o rigor científico da argumentação acerca da possibilidade de integração da norma antielisiva no ordenamento jurídico brasileiro a partir da existência de princípios e regras fundamentais relativas à tributação e às práticas de atos privados pelos particulares.

Entende-se como possível a tributação a partir de dois fatores concomitantes: a existência de uma norma prévia que estabeleça que dado tributo seja devido, hipótese de incidência. A aferição de uma situação de fenomênica que seja acoplada à previsão normativa hipotética, fato oponível. Se essas são as condições estruturadas constitucionalmente, pode-se argumentar acerca da possibilidade de aplicação da analogia em matéria tributária?

A finalidade específica da norma antielisiva é, em sua justificação interna, resguardar o Estado acerca da criatividade dos agentes privados em suas trocas econômicas. Dessa forma, a ação elisiva teorizada pela doutrina e pelos aplicadores do Direito se dá a partir do momento em que o particular realiza um ato que o retire da zona de incidência de uma norma tributária. Mas há que se falar em resguardar o Estado em relação aos particulares no que diz respeito à prática de atos jurídicos lícitos, previstos na própria legislação? Efetivamente, não. A lógica básica do Direito Público é que o Estado detém todas as ferramentas para alterar as condições de ação dos sujeitos ao deter, exclusivamente, o poder de estabelecer as normas de conduta. Ao privado, resta tão somente o estabelecimento da confiança, ou seja, da 
prospecção de justa expectativa de que aquelas condições postas no tempo e no espaço não se modificarão sem o rito necessário para tanto.

A partir disso, não se pode considerar a possibilidade de existência, validade, de norma geral antielisiva no ordenamento jurídico brasileiro a partir da Constituição Federal de 1988. Por mais que haja a necessidade arrecadatória por parte do Estado, as regras do jogo devem ser respeitadas. A norma contida no artigo 116, parágrafo único, do Código Tributário Nacional, não pode ser encarada como norma antielisiva a partir de uma argumentação científica, sob pena de se instaurar a quebra dos pilares do Estado de Direito: proteção da confiança, segurança jurídica e legalidade.

\section{PODEM AS CRIPTMOEDAS SER USADAS NO PLANEJAMENTO TRIBUTÁRIO, ESPECIALMENTE PARA EVASÃO FISCAL?}

No Brasil, para fins fiscais a Bitcoin ou outras moedas digitais devem ser consideradas commodite, sendo que a SRFB a equipara a ativo financeiro, podendo gerar ganho de capital na sua alienação, devendo ser declarada no imposto de renda como bens e direitos.

As transações realizadas com criptomoedas ocorrem na Blockchaim e são guardadas pela criptografia, ou seja, são anônimas e praticamente impossíveis de saber em que local ocorreu à operação, bem como seus reais titulares, pois no registro do Bitcoin na Blockchain o proprietário pode usar pseudônimo. Toda a operação é registrada na Blockchain, mas por não vincular ao titular, sua identificação dependerá de declaração do seu proprietário, é praticamente impossível identificar o verdadeiro proprietário da Bitcoin.

Esse ambiente virtual regido pelo anonimato e falta de lastro é o ambiente perfeito para se realizar operações com o objetivo de se encobrir o negócio jurídico praticado da SRFB, caracterizando o que se convencionou chamar de evasão fiscal, que em alguns casos configura sonegação fiscal, tipo penal contra a ordem tributária, prevista na Lei n. 8.137/90.

Como assevera Fernando Ulrich (2014, p 45), por ser a Bitcoin um pacote de dados, é possível que elas sejam usadas para transferir moedas, ações de empresas, contratos, micropagamentos, informações, contratos e propriedades. Assim, por poder carregar essas informações é que a Bitcoin pode ser utilizada com a finalidade de evadir divisas. 
Logo, o anonimato facilita afastar a prática de negócios jurídicos que configurariam fato gerador de determinado tributo do campo não da incidência, mas de reconhecimento por parte da administração tributária. Pratica similar ocorreu no passado com o sigilo bancário e com a utilização de ações ao portador por diversos tipos societários existentes em diferentes países, que serviam para proteger patrimônio de devedores, mas também de omitir fatos tributáveis ou guardar recursos financeiros protegidos da responsabilidade advinda da evasão fiscal.

Ressalte-se que não se tem conhecimento de estudos técnicos ou trabalhos científicos que trataram da temática do uso das criptomoedas na evasão fiscal, o que impede na metodologia adotada de se evidenciar trabalhos de campo que tenham confirmado a premissa ora desenvolvida. No entanto, seguramente a omissão de sua titularidade na declaração de bens e direitos seguramente acarretará a condição evasiva da operação, naturalmente se não realizada de forma intencional - omissão no preenchimento.

Dessa forma, não há dúvida no aspecto conceitual da possibilidade de se afirmar que a ausência da clara identificação nas transações realizadas permite uma ampliação no campo cada vez mais fechado dos ilícitos tributários enquadrados como evasão fiscal. As transações efetuadas no ciberespaço, conforme já explicado, são totalmente anônimas e não deixam lastro. Não há regulamentação e tampouco fiscalização de órgão governamental, sendo essa característica a principal fundamentação para pressupor que as criptomoedas podem ser utilizadas na evasão fiscal.

Apesar da obrigatoriedade de ter de declarar no Imposto de Renda a propriedade de criptomoeda como bens e direitos, a Receita Federal ainda não possui meios para saber seu quantitativo por parte de determinado contribuinte, quando foi pago ou quanto foi auferido de lucro com a especulação. Sendo assim, somente poderá ser considerado um planejamento tributário lícito quando devidamente informado ao órgão fiscal o formato exato e legal de sua realização por parte do seu proprietário.

Outro ponto que chama a atenção é a falta de local fixo onde as criptomoedas possam estar guardadas. Conforme explicado, a Blockchaim não possui servidor único e fixo estabelecido em determinada jurisdição. Os dados são compartilhados por todos os computadores da rede, o que dificulta sobremaneira, como já tratado, identificar a localização da criptomoeda. Essa característica pode ser usada para efetuar uma transação, por exemplo, 
no Brasil, mas que pode ser transferida pela rede para um país com baixa ou tributação inexistente.

Também importante ressaltar que existem técnicas que permitem mudar ou esconder o endereço IP dos computadores da rede, o que se torna outro empecilho aos órgãos fiscalizadores determinar de onde e a quem pertencem as criptomoedas. Sobre a questão da sua utilização na evasão fiscal, o Australian Taxation Office ${ }^{9}$ criou força tarefa para investigar as questões práticas sobre as moedas digitais. Entre as atividades está o rastreamento dos usuários das criptomoedas a fim de verificar os relatórios ficais.

$\mathrm{Na}$ realidade brasileira, no momento em que o contribuinte declarar a Bitcoin como ganho de capital na declaração do Imposto de Renda, é que o ente público conseguirá rastrear a criptomoeda, pois a ela está vinculada ao seu registro fiscal, sendo que qualquer operação realizada com a Criptomoeda e seu ganho de capital deverá ser declarada. Nesse caso se estará provavelmente diante de uma elisão fiscal.

A possível solução para evitar a evasão via Bitcoin no Brasil, para garantir que o incremento dos cofres públicos se dê de maneira respeitosa às premissas legais, é lançar mão dos próprios mecanismos do Estado que permitem a tributação: a legalidade, incluindo-se novas hipóteses típicas em matéria tributária. A questão arrecadatória na matriz de implementação de um Estado de bem-estar social, desenhado na Constituição Federal de 1988, é pedra angular. Mas ao mesmo tempo, para que haja a arrecadação, deve haver precisão terminológica e normativa.

Compreender essas questões é fundamental para que se possa rearticular o sistema tributário/financeiro brasileiro em base normativa sólida. A fluidez e a dinamicidade das relações privadas devem ser protegidas, sob pena de se instaurar verdadeiro Estado autoritário, onde o arbítrio impera. Nesse ponto, para que haja tributação deve haver legitimidade. Essa legitimidade se dá no âmbito da função legislativa, que representa a vontade dos particulares em sua amostragem política. Justamente por isso a regulamentação legal da matéria será o norte adequado para que as operações lastreadas em criptmoeda possam ser qualificadas como planejamento tributário, não passível de configuração, portanto, como evasão fiscal.

\footnotetext{
9 Studio Bitcoin. Disponível in: <https://www.studiobitcoin.com/escritorio-de-tributacao-da-australia-querevitar-evasao-fiscal-relacionada-ao-bitcoin/> . Acesso em 01 de ago. de 2018.
} 


\section{Considerações finais.}

As interações humanas tem se devolvido de maneira a ser tudo virtual. O trabalho, as transações financeiras, qualquer ato da vida tem algo da tecnologia digital envolvida. Nesse ambiente virtual foram criadas as criptomoedas, forma de moeda virtual que não é emitida pelo Estado e sim por softwares que integram a Blockchaim.

Conforme visto, as criptomoedas vêm despertando o interesse da comunidade jurídica devido às dúvidas e implicações jurídicas que causam em suas transações. Uma dessas implicações é na seara do Direito Tributário. Nos cenários da realização dos planejamentos tributários, poderiam as criptomoedas ser usadas como mecanismo de evasão fiscal? Ainda é muito cedo para responder a essa pergunta. Por ser uma temática nova, faltam estudos acadêmicos e dos órgãos governamentais que levantem dados precisos para responder essa indagação.

Apesar da SRFB entender que as criptomoedas devem ser declaradas no imposto de renda como ganho de capital, não é possível quantificar e saber o quanto foi pago e o valor auferido de lucro com a especulação, devido à falta de tecnologia que o possibilite. O que se pode concluir, mesmo com a falta de estudos e dados dos órgãos governamentais, é que o ambiente do ciberespaço que garante o anonimato, a dificuldade de estabelecer a localização e a quem pertence determinada criptomoeda, além de sua alta volatilidade e facilidade de transação, leva à conclusão de que as mesmas podem ser utilizadas na evasão fiscal.

\section{REFERÊNCIAS BIBLIOGRÁFICAS.}

ABREU, Jaqueline de Souza. Passado, presente e futuro da criptografia forte: desenvolvimento de novas tecnologias e regulação. Revista Brasileira de Políticas Públicas, Brasília, v. 7, n. 3, p. 25-42, dez. 2017. Disponível in:

<https://www.publicacoesacademicas.uniceub.br/RBPP/issue/view/238/showToc>. Acesso in: 25 jul. 2018.

ANDRADE, Mariana Dionísio de. Tratamento jurídico das criptomoedas: a dinâmica dos bitcoins e o crime de lavagem de dinheiro. Revista Brasileira de Políticas Públicas, Brasília, v. 7, n. 3, p. 45-59, dez. 2017. Disponível in: <https://www.publicacoesacademicas.uniceub.br/RBPP/issue/view/238/showToc>. Acesso in: 25 jul. 2018. 
BAL, Aleksandra. Does the tax Sector Need Blockchain? Disponível in: < https://www.ibfd.org/IBFD-Tax-Portal/News/New-White-Paper-Does-Tax-Sector-NeedBlockchain>. Acesso in 15 jul. 2018.

BAL, Aleksandra. Blockchain, initial coin offerings and other developments in the virtual currency market. Disponível in: < https://www.ibfd.org/IBFD-Products/JournalArticles/Derivatives-and-Financial-

Instruments/collections/dfi/html/dfi_2018_02_int_1.html>. Acesso in: 15 jul. 2018.

BRASIL. Constituição (1988). Constituição da República Federativa do Brasil.

Disponível in: < http://www.planalto.gov.br/ccivil_03/constituicao/constituicao.htm>. Acesso em: 15 jul. 2018.

BRASIL. Secretaria da Receita Federal do Brasil. Imposto Sobre a Renda - Pessoa Física Perguntas e Respostas. Ano calendário 2016 - Exercício 2017. Disponível in: <http://idg.receita.fazenda.gov.br/interface/cidadao/irpf/2017/perguntao/pir-pf-2017perguntas-e-respostas-versao-1-1-03032017.pdf>. Acesso em 20 de jul de 2018.

BRASIL. Comissão de Valores Mobiliários. Circular 1/2018/CVM/SIN. Disponível in <http://www.cvm.gov.br/export/sites/cvm/legislacao/oficios-circulares/sin/anexos/oc-sin0118.pdf >. Acesso em 20 de jul de 2018.

BRASIL. Banco Central do Brasil. Comunicado n 31.379, de 16 de novembro de 2017. Alerta sobre os riscos decorrentes de operações de guarda e negociação das denominadas moedas virtuais. Disponível in: $<$ https://www.bcb.gov.br/pre/normativos/busca/normativo.asp?numero=31379\&tipo=Comuni cado\&data $=16 / 11 / 2017>$. Acesso em 20 de jul. de 2018.

BRASIL. Câmara dos Deputados. Relator quer proibir emissão de moedas virtuais. Disponível in: <http://www2.camara.leg.br/camaranoticias/noticias/economia/551223-relatorquer-proibir-emissao-de-moedas-virtuais.html>. Acesso em 20 de jul de 2018.

Cresce o uso de Bitcoin para enviar dinheiro ao exterior

Disponível in: <https://istoe.com.br/cresce-o-uso-de-bitcoin-para-enviar-dinheiro-aoexterior/>. Acesso em 21 de jul de 2018.

DENNY, Danielle Mendes Thame; PAULO, Roberto Ferreira; CASTRO, Douglas de. Blockchain e Agenda 2030. Revista Brasileira de Políticas Públicas, Brasília, v. 7, n. 3, p. 122-141, dez. 2017. Disponível in:

<https://www.publicacoesacademicas.uniceub.br/RBPP/issue/view/238/showToc>. Acesso in: 25 jul. 2018.

Escritório de tributação da Austrália quer evitar a evasão fiscal relacionada ao Bitcoin. Disponível in: <https://www.studiobitcoin.com/escritorio-de-tributacao-da-australia-querevitar-evasao-fiscal-relacionada-ao-bitcoin/>. Acesso em 01 de ago. de 2018.

FOLLADOR, Guilherme Broto. Criptomoedas e competência tributária. Revista Brasileira de Políticas Públicas, Brasília, v. 7, n. 3, p. 80-104, dez. 2017. Disponível in: 
<https://www.publicacoesacademicas.uniceub.br/RBPP/issue/view/238/showToc >. Acesso in: 25 jul. 2018.

MARINHO, Maria Edelvacy Pinto; RIBEIRO, Gustavo Ferreira. A reconstrução da jurisdição pelo espaço digital: redes sociais, blockchain e criptomoedas como postulados de mudança.

Revista Brasileira de Políticas Públicas, Brasília, v. 7, n. 3, p. 143-156, dez. 2017.

Disponível in:

<https://www.publicacoesacademicas.uniceub.br/RBPP/issue/view/238/showToc>. Acesso in: 25 jul. 2018.

RIGGS, Wagner. Bitcoin deve continuar em queda", diz relatório do Goldman Sachs. Disponível in: $<$ https://portaldobitcoin.com/bitcoin-deve-continuar-em-queda-diz-relatoriodo-goldman-sachs/>. Acesso em 20 jul de 2018.

SOUZA, Ranidson Gleyck Amâncio. Território das criptomoedas: limites à regulamentação estatal quanto à circulação de moedas no ciberespaço e possíveis alternativas. Revista Brasileira de Políticas Públicas, Brasília, v. 7, n. 3, p.61-78, dez. 2017. Disponível in: <https://www.publicacoesacademicas.uniceub.br/RBPP/issue/view/238/showToc >. Acesso in: 25 jul. 2018.

SILVA, Felipe Rangel; TEIXEIRA, Rodrigo Valente Giublin. Bitcoin e a (im)possibilidade de sua proibição: uma violação à soberania do Estado? Revista Brasileira de Políticas

Públicas, Brasília, v. 7, n. 3, p. 106-120, dez. 2017. Disponível in:

<https://www.publicacoesacademicas.uniceub.br/RBPP/issue/view/238/showToc>. Acesso in: 25 jul. 2018.

ULRICH, Fernando. Bitcoin - A moeda na era digital. In MEDEIROS, Danilo Soares Pacheco de; SERPA, Alexandre Luiz de Oliveira; LIMA, Leonardo de Siqueira. Um pequeno passo para a liberdade. A era da disrupção. $3^{\text {a }}$ ed. - São Paulo: LVM, 2017. 